\title{
The Determination of Factors Influence Noise Pollution in Malaysia using Fuzzy Logic
}

\author{
Mohd Fazril Izhar Mohd Idris ${ }^{1 *}$, Nur Afifah Zainol Abidin ${ }^{2}$, Khairu Azlan Abd Aziz ${ }^{3}$ \\ ${ }^{1,2,3}$ Faculty of Computer and Mathematical Sciences, Universiti Teknologi MARA, Perlis Branch, Arau \\ Campus, 02600 Arau, Perlis, Malaysia \\ Corresponding author: *fazrilizhar@uitm.edu.my \\ Received Date: 24 August 2020 \\ Accepted Date: 2 October 2020
}

\begin{abstract}
Nowadays, the economy of our country has increased, so the use of transport, whether on land or by air, has also increased. This will lead to noise pollution, which will have an impact on human health. Noise pollution was an unpleasant sound that could have a negative impact on human health, such as sleep disturbance, hearing loss, annoyance, and stress. There are many factors that can cause noise pollution such as road traffic, aircraft, commercial construction, industrial and manufacturing noise. Therefore, the aim of this study is to determine the factor that influences noise pollution in Malaysia using Fuzzy Logic. The determination of factors that affect noise pollution in Malaysia using the Fuzzy Logic approach includes the determination of input and output variables, Fuzzification, Fuzzy Rule-Based, Fuzzy Inference Method and Defuzzification. In Defuzzification which is the last stage for Fuzzy logic, Centroid method used since it can give a result with more accurate and flexible. This study used road traffic noise, aircraft noise, industrial and manufacturing noise and commercial construction as factors for noise pollution, as well as input variables. This method was used to determine which factors have the most influence on noise pollution. The results of this study show that road traffic noise and industrial and manufacturing noise were factors which had an impact on noise pollution with a maximum value of 82. This shows that the aim of this study has been achieved.
\end{abstract}

Keywords: Noise Pollution, Fuzzy Logic, Centroid Method, Road Traffic Noise, Industrial and Manufacturing Noise, Commercial Construction, Aircraft Noise

\section{INTRODUCTION}

As a person living in megacity, it can cause a lot of trouble for people. This is because the fast-growing industry and the population of vehicles in the town have had an impact on the environment, such as noise pollution. According to the World Health Organisation (WHO, 2011), sound pollution is an undesirable sound that can be annoying, disruptive, and physically painful and that is usually caused by people or machines. Noise pollution is one of the environmental pollutions that can have a negative impact on human health and on daily life.

Noise pollution has occurred as a human health disorder (De, Swain, Goswami, \& Das, 2017). At the construction site, the sound of large machines is the main source of undesired sound. Big machines are the main equipment in the construction sector that can produce high noise levels (Ankita et al., 2016). The motivation behind this study is to study the level of noise pollution that can affect people's health, particularly those of construction workers. This is because work on the construction site has made them directly exposed to unwanted noise. However, the sources of unpleasant sound come not only from large construction machines, but also from traffic, television, dog barking, large trucks and industrial aircraft equipment (Muhammad Anees, Qasim, \& Bashir, 2017). 
Noise pollution is not only caused by the noise of large construction machines but is also caused by other factors such as road and aircraft noise. These factors also have an influence on noise pollution. According to Pyko et al. (2017), road traffic is among the other factors that have the most impact on noise pollution. The reason is that the demand for cars is also increasing due to the growing population. In addition, aircraft are also one of the factors that lead to noise pollution. High levels of aircraft noise can have an impact on human health, including the risk of stroke, coronary heart disease, and cardiovascular disease (Anna et al., 2013).

As Sinar Harian (2019) reported, the awareness regarding the level of noise pollution in Malaysia is low. It also reported that even though the Occupational Safety and Health Act 1994 has been enacted since June 1, the employer and worker are still not paying much attention to this issue. However, the construction industry is the industry that cannot be hindered by creating a loud noise. The source of this unwanted noise coming from the machines that have been used at construction sites. This situation can give many negative impacts on people such as workers who work around the construction site. Not only give the impact to the worker, but also to people who stay around the construction site.

In addition, working in a place that directs a loud noise will have an immediate effect on the worker's hearing. This happens when there is no awareness of noise pollution in the workplace. Noise pollution not only affects workers but has also influenced all people who are exposed to noise in their daily lives. Although studies (Nagarajappa et al., 2015), (Prakash \& Veerappa, 2015), (Slabbekoorn, 2019), have been proposed on the effects of noise pollution on human health, there are still no studies on the factors that have a greater impact on the level of noise in Malaysia. The fuzzy logic model has therefore been established to determine the strongest factors affecting noise pollution in Malaysia.

\section{METHODOLOGY}

\section{a) Fuzzy Logic}

In this study, the fuzzy logic used to determine the factor that influences noise pollution in Malaysia. In the first stage, inputs and output variables will be identifying then defines the linguistic variables and terms. Next, crisp input will be converting into a fuzzy value in a fuzzification process. The next stage is setting the rules which is called a fuzzy rule based. The fuzzy rule models will deal with linguistic descriptions. The stage then followed by the Fuzzy Inference Evaluation process. In generating the output, the rules and information are important. An "IF-THEN" rule has the form: "If $\mathrm{x}$ is A then $\mathrm{y}$ is B", where A and $\mathrm{B}$ are the linguistic values to formulate the conditional statement. The last stage in fuzzy logic is a defuzzification process which is obtaining the result in determining the strongest factor that influences noise pollution. Figure 1 shows the framework of fuzzy logic.

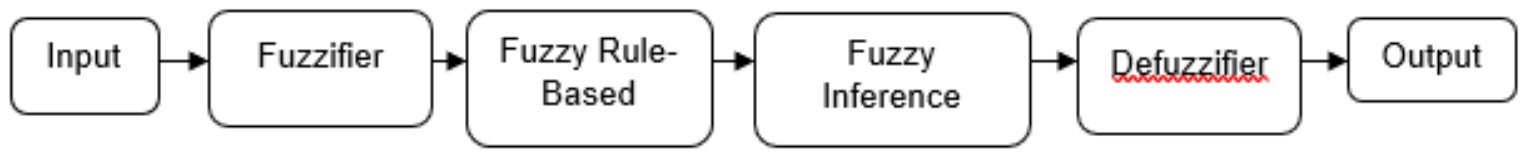

Figure 1: The Framework of Fuzzy Logic

There are four input and one output as linguistic variables that affect the noise pollution in Malaysia. The inputs taken for this study are road traffic noise, aircraft noise, commercial construction and industrial and manufacturing noise. While the output for this study is noise level. This study used primary data using an expert from the Department of the Environment Malaysia. Mamdani model have been used as the 
inference engine since its suitability with the inputs. Figure 2 shows the input variables and output variable.

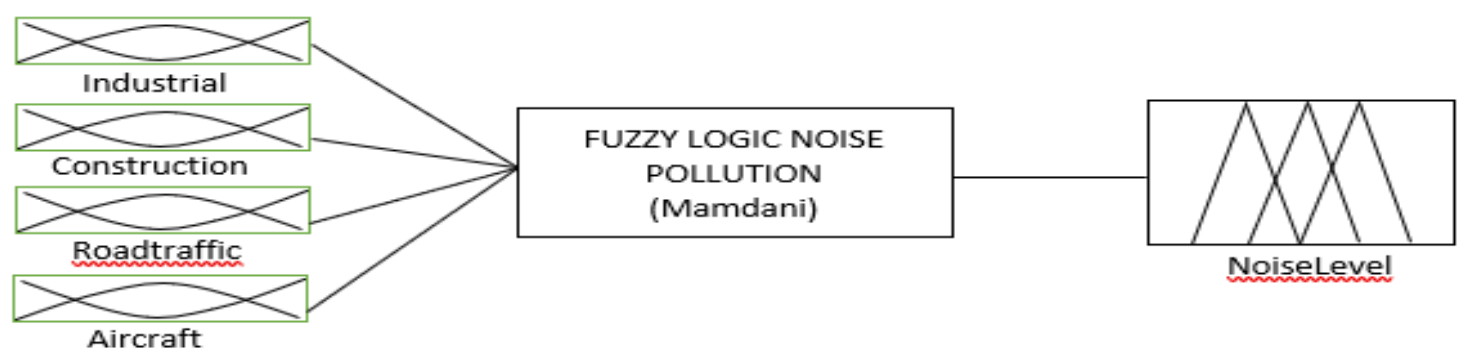

Figure 2: Four Inputs and an Output Variables

\section{b) Input Membership Function}

The inputs and output variable of this study has been divided into three categories with set used in the membership function. Table 1,2,3 and 4 shows the parameter for the linguistic variable for each input while Figure 3,4,5 and 6 depicts the membership functions for each input. The membership function for variable low and high are trapezoidal, while for medium is triangular membership function.

i. Industrial and Manufacturing Noise

Table 1: Parameter for the linguistic variable of Industrial and Manufacturing Noise Parameter Linguistic Variables

$[0,0,25,50]$

$[25,50,75]$

$[50,75,100,100]$
Low

Medium

High

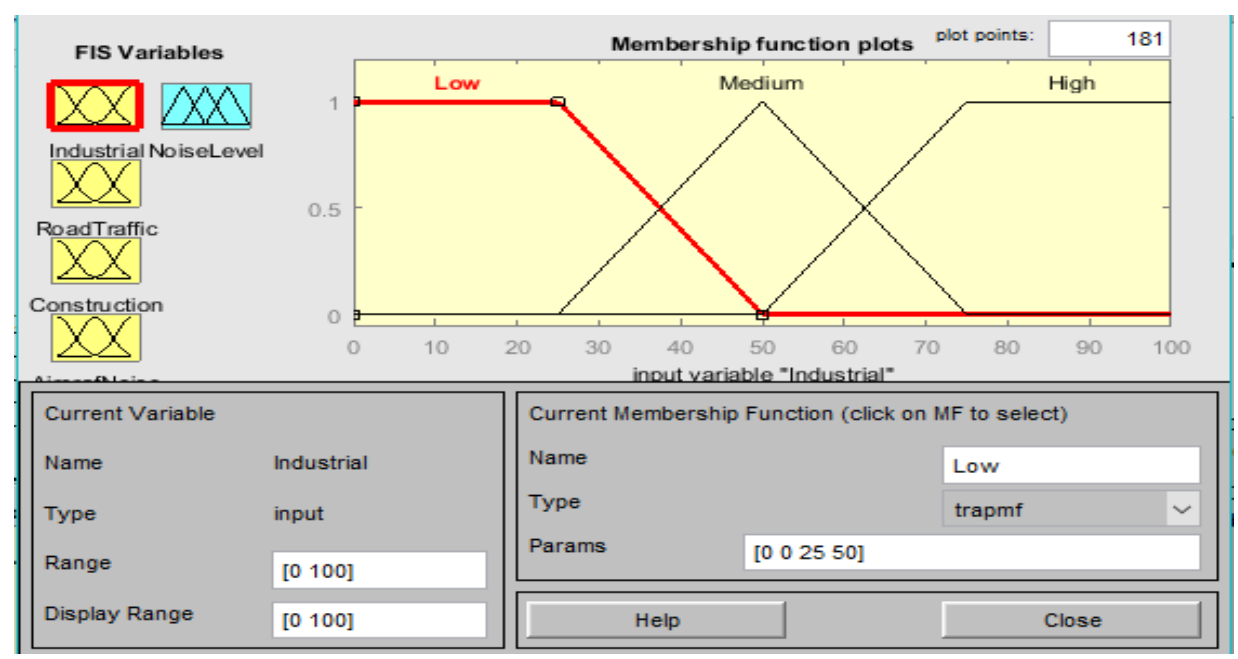

Figure 3: Membership function for Industrial and Manufacturing Noise 


\section{ii. Road Traffic Noise}

Table 2: Parameter for the linguistic variable of Road Traffic Noise

Parameter Linguistic Variables

\begin{tabular}{cc}
\hline$[30,30,45,60]$ & Low \\
{$[45,60,75]$} & Medium \\
{$[60,75,90,90]$} & High \\
\hline
\end{tabular}

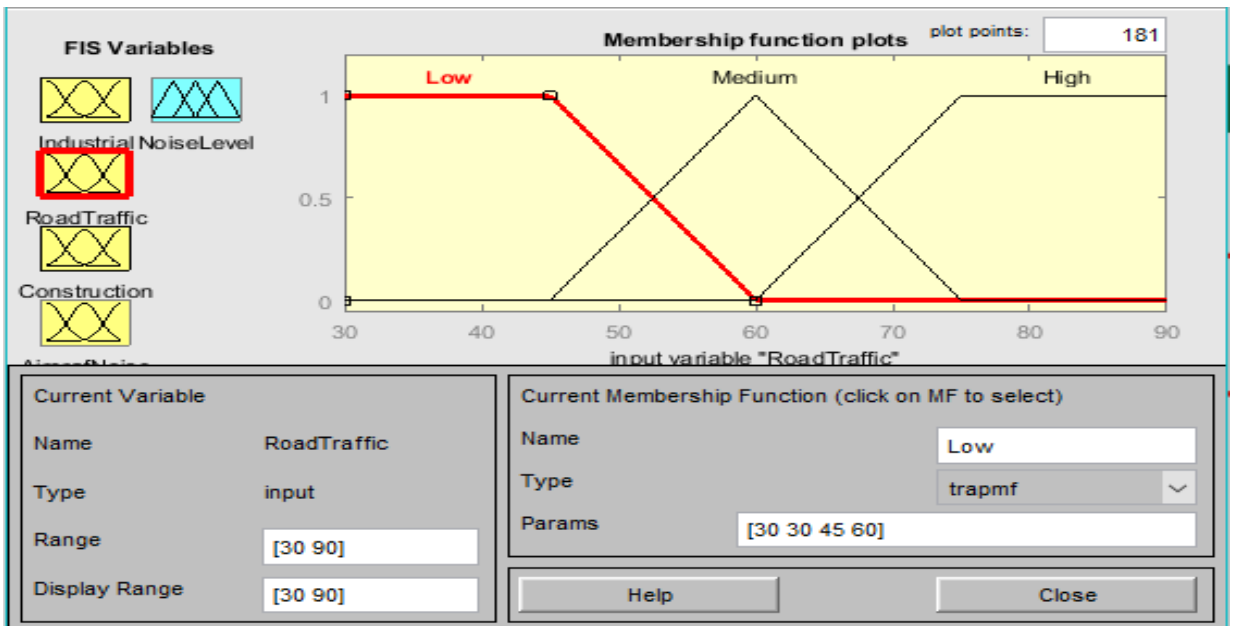

Figure 4: Membership function for Road Traffic Noise

iii. Commercial Construction

Table 3: Parameter for the linguistic variable of Commercial Construction

\section{Parameter}

$[0,0,25,50]$

$[25,50,75]$

$[50,75,100,100]$

\section{Linguistic Variables}

Low

Medium

High

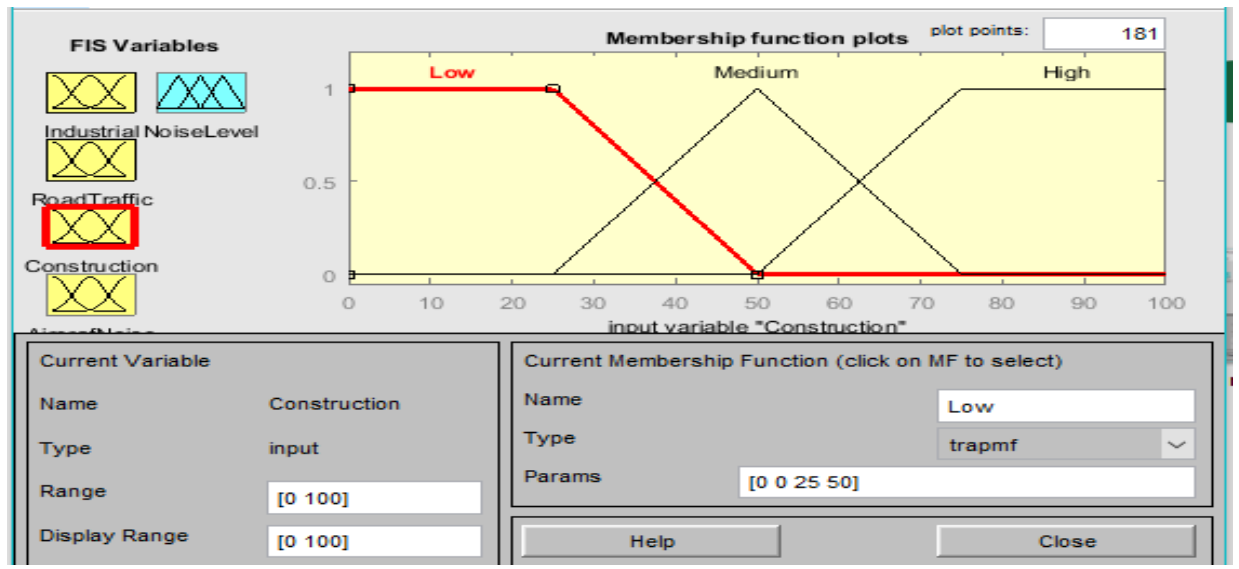

Figure 5: Membership function for Commercial Construction 
iv. Aircraft Noise

Table 4: Parameter for the linguistic variable of Aircraft Noise

Parameter Linguistic Variables

\begin{tabular}{cc}
\hline$[30,30,45,60]$ & Low \\
{$[45,60,75]$} & Medium \\
{$[60,75,90,90]$} & High \\
\hline
\end{tabular}

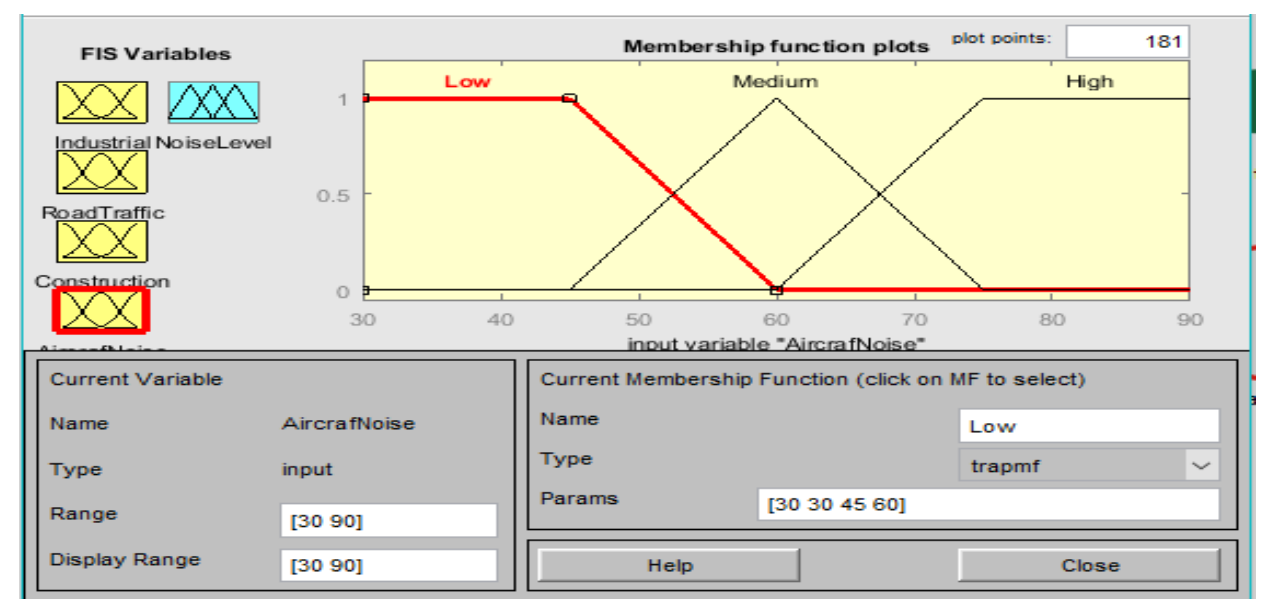

Figure 6: Membership function for Aircraft Noise

\section{c) Output Membership Function}

In this study, noise level is an output variable which has three levels: Low Risk, Medium Risk and High Risk as shown in Figure 7. For low risk and high risk are defined by the membership function trapmf (trapezoidal). Meanwhile, for medium risk is defined by the membership function trimf (triangular).

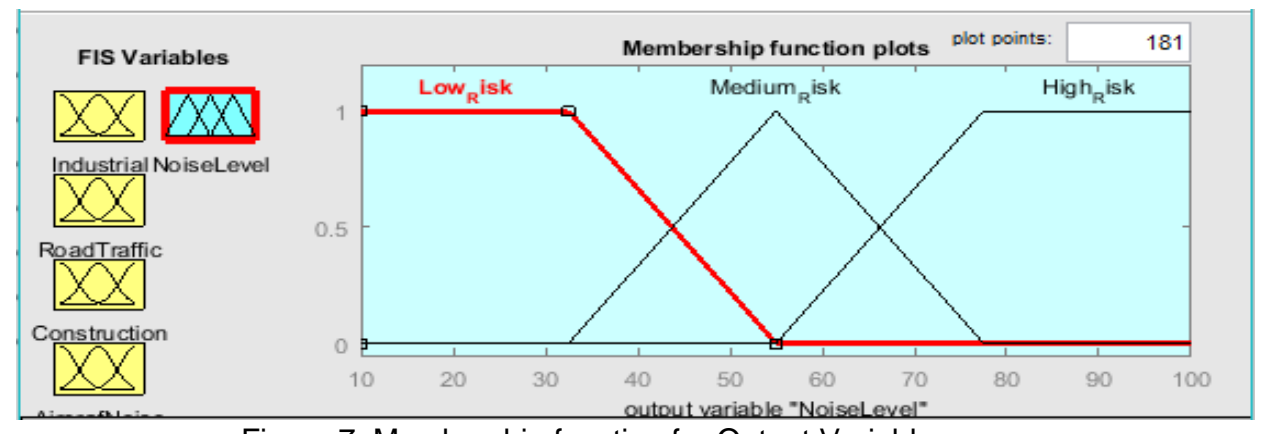

Figure 7: Membership function for Output Variable

\section{d) Rules Construction}

Since there are four inputs and one output with three linguistic expressions in this research, there are therefore 81 rules where $3^{4}(3 \times 3 \times 3 \times 3)$ are generated. The following is part of list of rules that was generated. 
1. If (Industrial is High) and (RoadTraffic is High) and (Construction is High) and (AircraftNoise is High) then (NoiseLevel is High)

2. If (Industrial is High) and (RoadTraffic is High) and (Construction is High) and (AircraftNoise is Medium) then (NoiseLevel is High)

3. If (Industrial is High) and (RoadTraffic is High) and (Construction is High) and (AircraftNoise is Low) then (NoiseLevel is High)

77. If (Industrial is Low) and (RoadTraffic is Low) and (Construction is Medium) and (AircraftNoise is Medium) then (NoiseLevel is Low)

78. If (Industrial is Low) and (RoadTraffic is Low) and (Construction is Medium) and (AircraftNoise is Low) then (NoiseLevel is Low)

79. If (Industrial is Low) and (RoadTraffic is Low) and (Construction is Low) and (AircraftNoise is High) then (NoiseLevel is Low)

80. If (Industrial is Low) and (RoadTraffic is Low) and (Construction is Low) and (AircraftNoise is Medium) then (NoiseLevel is Low)

81. If (Industrial is Low) and (RoadTraffic is Low) and (Construction is Low) and (AircraftNoise is Low) then (NoiseLevel is Low)

The rules are then keyed in into Matlab software as shown in Figure 8.

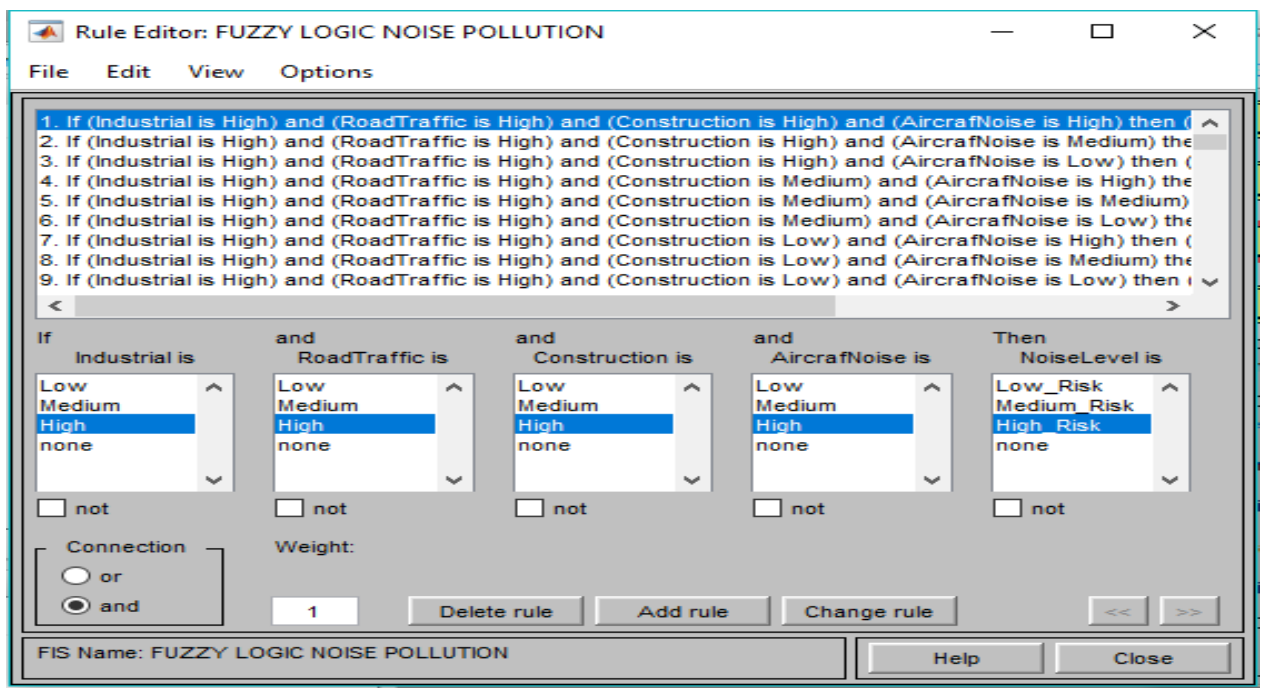

Figure 8: MATLAB-rule editor for 81 rules

\section{FINDINGS AND DISCUSSION}

The noise level status was achieved by using the Fuzzy Inference System Editor in the MATLAB software. The strongest factor that influences noise pollution was determined from the level of noise. For instance, if the input value for Industrial is 75, Road Traffic is 83.1, Construction is 78.5, and Aircraft Noise is 74 , the output value of which is Noise Level is 82.5. Figure 9 shows the rule viewer from the Fuzzy Logic Noise Pollution Matlab software. 


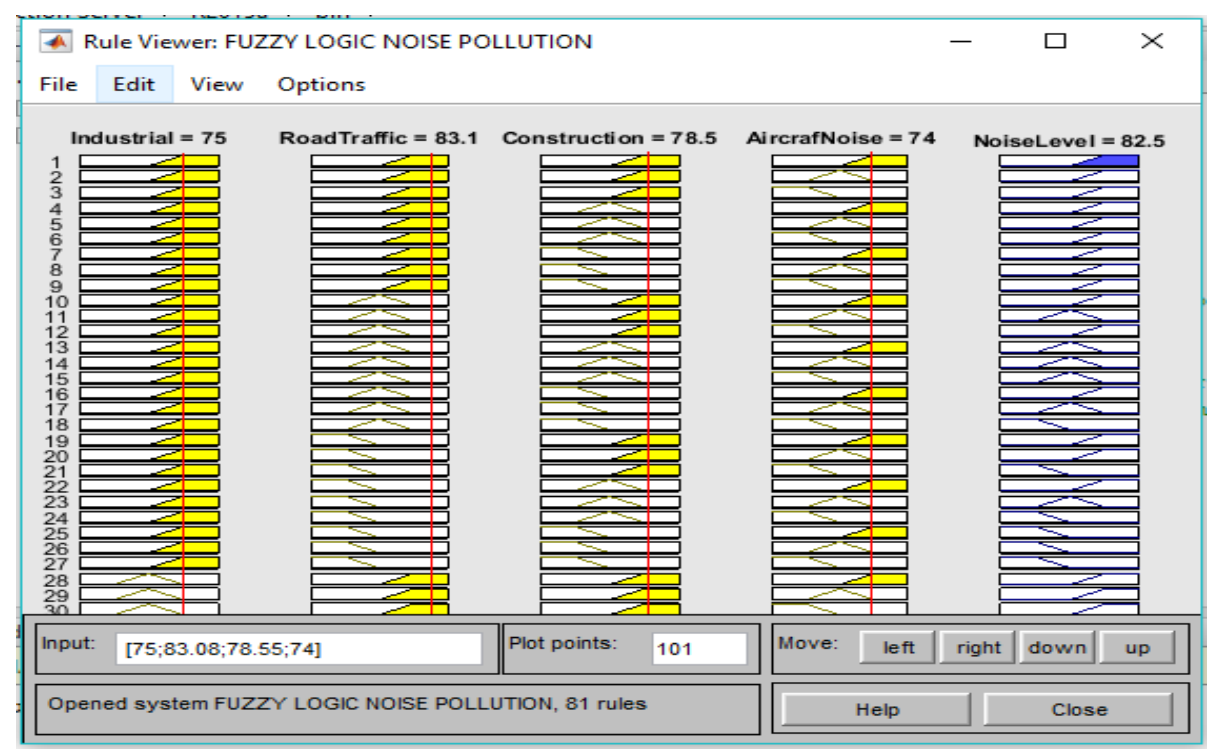

Figure 9: Rule Viewer of Fuzzy Logic Noise Pollution

The 2-D curve in Figure 10,11,12 and 13 shows the determination of the strongest noise pollution factor. The noise level of the four factors was compared and the maximum noise level values was then determined.

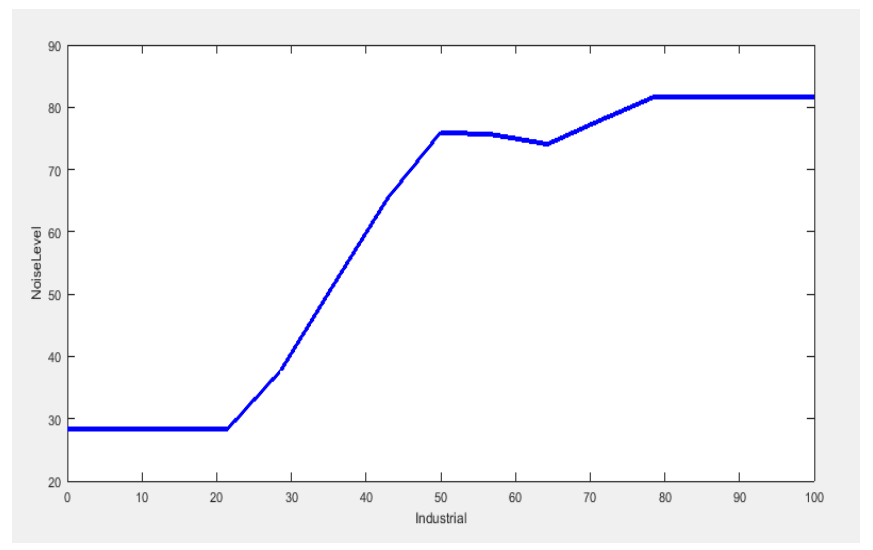

Figure 10: The Noise Level of Industrial

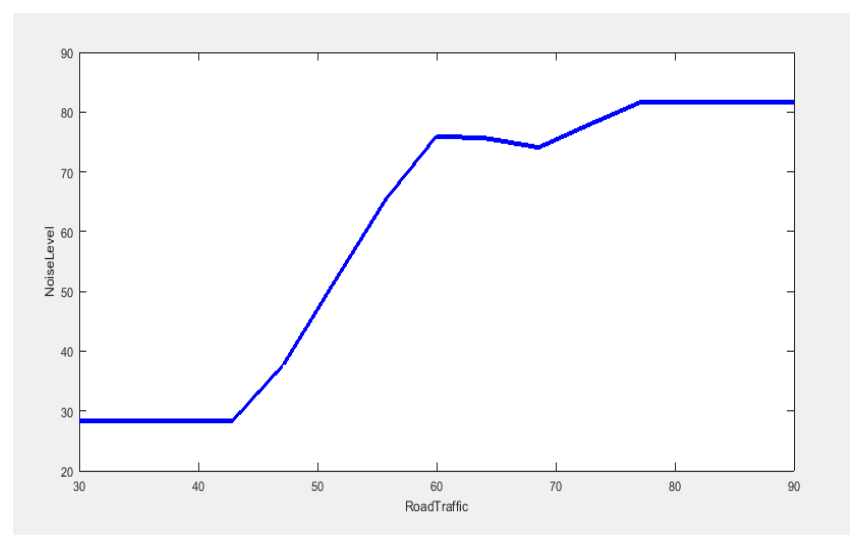

Figure 11: The Noise Level of Road Traffic 


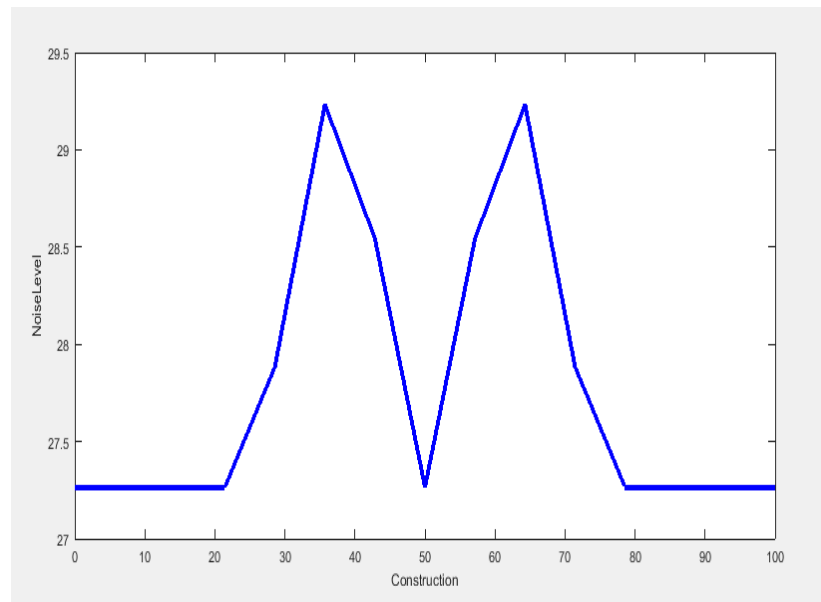

Figure 12: The Noise Level of Construction

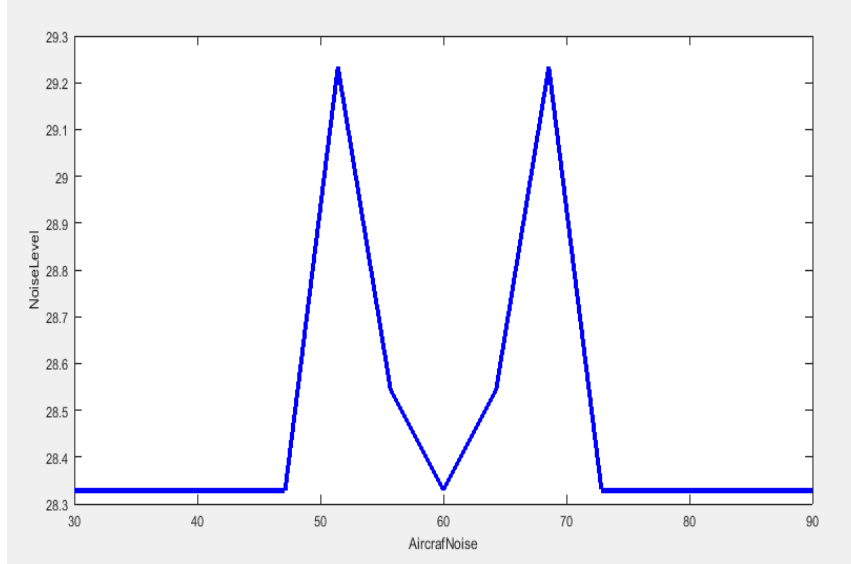

Figure 13: The Noise Level of Aircraft Noise

Table 5: The Values of Noise Level of Factors Noise Pollution

\begin{tabular}{cc}
\hline Factors & Maximum Value \\
\hline Industrial & 82 \\
Road Traffic & 82 \\
Construction & 29.4 \\
Aircraft Noise & 29.2 \\
\hline
\end{tabular}

Table 5 shows the maximum level of the noise levels of the four noise pollution factors that are Industrial and Manufacturing, Road Traffic Noise, Commercial Construction and Aircraft Noise, the noise levels obtained are 82, 82, 29.4 and 29.2, respectively. Based on 2-D curves, it can be stated that industrial and road traffic had a higher impact on noise levels compared to construction and aircraft noise. It shows that the noise from the vehicles on the road and on the highway has a greater impact on noise pollution. As in the industrial sector, the use of large machines has an impact on noise pollution in Malaysia. 


\section{CONCLUSION}

Noise pollution is one of the most important environmental pollutions in the world. Everyone needs to be alerted to this type of pollution because it can have an impact on human health. In conclusion, Fuzzy Logic is an effective method of determining the strongest noise pollution factor in Malaysia since it has a simple framework and construct with the natural language can make the valuation to be more understandable especially in terms of public consideration. The study focused on the factors that influence noise pollution, such as industrial and manufacturing noise, road traffic noise, commercial construction, and aircraft noise. As a result of these parameters, 81 rules-based were generated using the IF-THEN rules. All these rules have been used to determine the noise level for each parameter, and then, from the noise level status, the maximum value will be the strongest factor that influences noise pollution. The output obtained from Matlab shows that industrial manufacturing and road traffic noise are the strongest factors affecting noise pollution, the maximum value of these factors which is 82 . This means that the fuzzy logic model can be used to determine the strongest factor affecting noise pollution. This research has therefore achieved the objective set out which is to identify the strongest influence factor of noise pollution in Malaysia using Fuzzy Logic.

\section{REFERENCES}

Ankita, I. K., Devika, G., Lakshmi Priya, K., Remya, R., \& Jayamohan, J. (2016). Applications Of Geosynthetics In Embankments- A Review. International Advanced Research Journal In Science, Engineering, And Technology (IARJSET), 5(1), 31-41.

Anna, L., Blangiardo, M., Fortunato, L., Floud, S., De Hoogh, K., Fecht, D., Ghosh, R. E., Laszlo, H. E., Pearson, C., Beale, L., Beevers, S., Gulliver, J., Best, N., Richardson, S., \& Elliott, P. (2013). Aircraft Noise And Cardiovascular Disease Near Heathrow Airport In London: Small Area Study. BMJ (Online), 347(7928), 9-12.

De, S. K., Swain, B. K., Goswami, S., \& Das, M. (2017). Adaptive Noise Risk Modelling: Fuzzy Logic Approach. Systems Science And Control Engineering, 5(1), 129-141.

Muhammad Anees, M., Qasim, M., \& Bashir, A. (2017). Physiological And Physical Impact Of Noise Pollution On Environment. Earth Sciences Pakistan, 1(1), 8-10.

Nagarajappa.D.P, Priyanka P Shivdev, Lokeshappa.B, A. K. (2015). Fuzzy Logic Technique for Noise Induced Health Effects in Mine Site. International Journal of Innovative Research in Science, Engineering and Technology, 04(07), 5096-5103. https://doi.org/10.15680/ijirset.2015.0407009

Prakash, T. N., \& Veerappa, B. N. (2015). Interpretation of Noise Pollution Effects on Human Being using Fuzzy Logic Techniques. International Journal of Computer Science and Mobile Computing 4(4), 670-683.

Pyko, A., Eriksson, C., Lind, T., Mitkovskaya, N., Wallas, A., Ögren, M., Östenson, C.-G., \& Pershagen, G. (2017). Long-Term Exposure To Transportation Noise In Relation To Development Of Obesity-A Cohort Study. Https://Doi.Org/10.1289/EHP1910

Sinar Harian Online (2019, July 23). Tahap kesedaran pencemaran bunyi di Malaysia masih rendah. Retrived (November 30, 2019), from https://www.sinarharian.com.my/article/39323/BERITA/Nasional/Tahapkesedaran-pencemaran bunyi-di-Malaysia-masih-rendah 
Slabbekoorn, H. (2019). Noise pollution. Current Biology, 29(19), R957-R960. https://doi.org/10.1016/j.cub.2019.07.018

WHO (2011). Burden of Disease from Environmental Noise, JRC 